\title{
Acciones, Sistemas Normativos o Creencias ¿DÓNDE SE FUNDAMENTA LA VIOLENCIA?
}

\author{
Actions, Normative Systems or Beliefs: Where is Violence Based? \\ DAVID SUÁREZ-RIVERO \\ Universidad Vasco de Quiroga, Morelia, Universidad Autónoma de Tlaxcala, MÉXICO \\ darisua@gmail.com
}

\begin{abstract}
In this paper, I evaluate the concept of violence. I explore hypothetical cases which let us establish conditions or criteria for an action to be considered violent. I start with the idea that an action is violent when it breaks rules or norms that are established by social systems, which are based on belief systems. I conclude that we need to examine the belief systems, where the social systems are based, in order to eradicate any kind of action that could break rules or norms.
\end{abstract}

Keywords: Violence $\bullet$ actions $\bullet$ normative systems $\bullet$ belief systems

\section{Introducción}

Los diferentes tipos de violencia que se suscitan como consecuencia de las relaciones humanas son uno de los temas que preocupa y ha preocupado a lo largo de la historia. Encontramos violencia de género, violencia infantil, violencia en la familia, violencia en la pareja, violencia hacia los animales, violencia hacia el medio ambiente, entre otras muchas.

Encontramos también una diversidad de propuestas para explicar, ${ }^{1}$ detectar $^{2} \mathrm{o}$ abolir dicha violencia. ${ }^{3}$ Por ejemplo, hay propuestas sociales de cómo prevenir y ponernos a salvo de acciones violentas; ${ }^{4}$ propuestas morales que tratan de detectar cuándo alguien está sufriendo violencia; ${ }^{5}$ propuestas teóricas que nos describen sistemas que generan violencia. ${ }^{6}$

El concepto violencia está en discursos diversos. Pese a ello, hay pocos estudios que se preocupan por indagar semánticamente el concepto, ${ }^{7}$ cómo definirlo, ${ }^{8}$ lo común que tienen diferentes acciones que son calificadas como violentas. ${ }^{9}$ Es decir, en lugar de detenerse a estudiar el concepto mismo, muchos estudios retoman una idea de violencia y, partiendo de ella, desarrollan propuestas diversas. ${ }^{10}$ Esto, sin embargo, no es reprochable, dado que su objeto de estudio no es el uso o el significado del término, sino los contextos sociales donde se presenta la diversidad de situaciones violentas. 
Uno de los compromisos de la filosofía práctica es abordar y proponer soluciones a temas como el de violencia. A diferencia de los filósofos anteriormente mencionados, los cuales han apelado a los fenómenos mismos, yo propongo hacerlo, siguiendo una tradición analítica, a través de un análisis conceptual y un cúmulo de ejemplos.

Sugiero, así, examinar cuáles son los conceptos cercanos al concepto de violencia y cuáles se alejan, revisando casos concretos y elaborando experimentos mentales que reflejen situaciones reales. Esto permitirá delimitar y determinar qué es aquello que podrían tener en común los diferentes eventos, sean psicológicos, sociales, emocionales, entre otros, en los que se considera a una acción violenta, y cuáles son los criterios, si los hay, para determinar cuándo una acción puede ser considerada como tal. Esto nos permitirá clarificar y entender los fenómenos que calificamos como violentos.

En el artículo procedo, así, de la siguiente manera. En el apartado 1 planteo el problema y discuto dos propuestas de cómo determinar acciones violentas. En la sección 2 establezco un parámetro que nos permita discernir cuándo una acción es violenta. En el apartado 3 muestro un parámetro alterno que podría refutar al primero. En la sección 4 evidencio que dicho criterio es respaldado en una idea errada y muestro cómo mi propuesta se mantiene, apelando a un principio de permisibilidad. En el apartado 5 planteo objeciones a dos de mis principales ideas, respondiendo puntualmente a todas ellas en la sección 6. Asimismo, en el apartado 7 muestro las ventajas de mi propuesta. Finalmente, en la sección 8 evalúo un reforzamiento de mi propuesta y muestro por qué no se requiere.

\section{Acciones violentas: casos y propuestas}

Consideremos la siguiente oración:

(1) Joan murió ahorcado.

Si la oración (1) es aseverada en el contexto de un juicio, donde Joan fue declarado culpable y condenado a la horca por matar a sus hijos, diremos que Joan fue ajusticiado.

Algo distinto sucede cuando (1) es aseverada en un contexto diferente, digamos en el que un hombre entra a la casa de Joan y, por placer, lo cuelga del tejado. En este contexto diríamos que Joan fue violentado. Si en ambos contextos la acción es la misma, ¿en qué yace la diferencia?

La diferencia parece darse en el hecho de que si se ahorca a alguien de manera legal - es decir, siguiendo leyes y normas que justifican o respaldan determinadas acciones, como el de ahorcar a alguien porque ha atentado contra una ley o norma, 
como la de no matar - no se le violenta, sino que se le ajusticia. Una persona, así, solamente es violentada cuando no se siguen leyes o normas que legitiman la acción.

Hay, sin embargo, una interpretación distinta a la anterior, a saber: que Joan fue, en último término, violentado en ambos contextos, solamente que en el primero las leyes permiten ahorcarlo porque ha infringido el orden social, mientras que en el segundo no hay ninguna ley que respalde dicha acción. Así, no importando si hay o no una ley que respalde ahorcar a alguien, una persona ahorcada es siempre violentada, sea ya como resultado de un juicio o del placer deliberado.

Consideremos ahora la siguiente oración:

(2) Juan golpea a María.

Si consideramos la oración (2) dentro de un contexto donde Juan hace uso de la fuerza cada vez que su esposa María tiene una opinión diferente, y no emplea dicha fuerza con personas masculinas con las que difiere en punto de vista, diremos que María está sufriendo violencia de género.

Esto cambia cuando consideramos (2) en un contexto donde Juan y María tienen prácticas sadomasoquistas. Aquí diríamos que María goza cuando Juan hace uso de la fuerza. ¿Cuál es la diferencia que yace en estos contextos frente al hecho de que Juan golpea a María?

La diferencia radica en que hay prácticas consentidas que obedecen a placeres atípicos que legitiman que María no está sufriendo violencia de género. Fuera de estas prácticas consentidas, María estaría sufriendo violencia de género siempre que es golpeada por Juan.

Como en el caso de (1), hay también aquí una interpretación distinta, a saber, que María es, en último término, violentada en ambos contextos, no importando su consentimiento. Es decir, una mujer es siempre violentada cada vez que se usa la fuerza en contra de ella, aun en contextos donde ella lo consienta.

Muy cerca del ejemplo anterior están también casos donde se puede insertar la siguiente oración:

(3) La madre golpea al hijo.

Dado un contexto en el que se cree que los padres tienen el deber de corregir a sus hijos frente a acciones socialmente intolerables, (3) podría ser considerada como una oración donde la madre es una mujer responsable y digna de respeto.

Sin embargo, si la madre sufriera problemas sentimentales o emocionales, y descargara su malestar usando la fuerza contra su hijo, al escuchar (3) podríamos acusar a la madre de violencia infantil. Una vez más, ¿̇cuál es la diferencia en estos contextos? 
En el primer contexto hay algo que respalda a la madre, a saber: el hecho de que los padres tienen que corregir a los hijos. En el segundo contexto, sin embargo, no aparece dicho hecho que respalda el uso de la fuerza de la madre sobre el hijo.

Como en el caso de (1) y (2), en (3) también hay una interpretación alterna, la de que en ambos contextos se está violentando al hijo, solamente que en el primero hay una aceptación social que exime a la madre de violencia infantil. Es decir, un niño es violentado siempre que se usa la fuerza hacia él, no importando si hay prácticas sociales que lo respalden.

Consideremos un caso donde elrespaldo sea menos explícito y el uso de la fuerza no esté presente. Pensemos, por ejemplo, en la siguiente oración:

(4) Trabajaste muy bien, negro.

Si decimos que (4) es aseverada por el capataz de una finca, diríamos que el capataz está siendo racista.

Digamos, sin embargo, que no es el capataz quien profiere (4), sino que es la esposa del hombre aludido, la cual basa su comentario en el aspecto que presenta su marido cuando llega a casa devastado. En este contexto, no diríamos que la esposa está siendo racista, sino que está siendo afectiva hacia su marido. ¿Qué hace que, en contextos diferentes, (4) tome rumbos distintos, uno de ellos como agresión y el otro como muestra de amor?

En el caso de la oración (1) son las leyes o normas las que respaldan que ciertas acciones sean eximidas de aquellas que son consideradas violentas. En el caso de las oraciones (2) y (3) son las prácticas sociales que eximen a ciertas acciones de ser consideradas violentas. En el caso de (4) hay algo distinto: es la intención del hablante que hace que esta sea proferida para agredir o para mostrar afecto. Es decir, según la intención, (4) expresaría un contenido diferente: en el caso del capataz, (4) diría algo así como "trabajaste muy bien, animal", mientras que, en el caso de la esposa, (4) diría algo así como "trabajaste muy bien, amor".

¿Cómo proceder ante todo esto? ¿Es legítimo decir que si una acción,- - sea esta física o verbal - es respaldada por algo, - sea una ley o norma o práctica o intención - , dicha acción puede ser eximida de ser considerada violenta? Es decir, ¿una acción deja de ser violenta si es respaldada por una ley, una norma, una práctica o una intención?

En el resto del artículo ofrezco una propuesta con la que respondo no sólo a las preguntas formuladas anteriormente, sino también a lo siguiente: ¿son ciertas acciones, sean estas físicas o verbales, violentas por sí mismas? Si no es el caso, como parecen sugerirnos los ejemplos anteriores, ¿hay parámetros o criterios que sirvan como dispositivos para determinar violentas a ciertas acciones físicas o verbales? $\mathrm{O}$, mejor aún: ¿aquello que se considera violento está basado en sistemas de creencias? Si es así, ¿bajo cierto sistema de creencias podemos atribuir como violentas a ciertas 
acciones que en otro sistema de creencias no se considerarían así? ¿Cuáles son los compromisos adquiridos si aceptamos que lo que es violento está basado en un sistema de creencias, lo cual puede no ser compartido por otros sistemas de creencias? Más aun: ¿de qué manera podemos abordar y proponer soluciones a todas aquellas acciones que caen en el conjunto de acciones violentas?

\section{Criterio para identificar acciones violentas}

Sugiero el siguiente criterio para discernir acciones violentas de aquellas que no lo son:

(R) Una acción física o verbal $\mathbf{x}$ es considerada violenta si y sólo si $\mathbf{x}$ rompe cierta regularidad o normatividad establecida por una comunidad.

Pensemos, por ejemplo, en la oración (1): la persona que entra a la casa de Joan y lo cuelga del tejado rompe con cierta normatividad, a saber: la de la ley establecida por la comunidad. Por ello es que la acción cometida es considerada violenta. Esto no es así, como puede observarse, cuando Joan es colgado como resultado de una sentencia en un juicio legal. La corte, respaldada en leyes, ajusticia, pero no violenta, a Joan por haber matado a sus hijos.

Algo parecido sucede con (2) y (3): fuera de ciertas prácticas atípicas consentidas, Juan estaría cometiendo violencia de género, al romper con cierta regularidad o normatividad, golpeando a María; asimismo, fuera de una aceptación social — la cual acepta que una parte de la educación consista en dar ocasionalmente un correctivo físico - , la madre estaría cometiendo violencia infantil, al romper cierta regularidad o normatividad, golpeando al niño.

En el caso de (4), la esposa no rompe con cierta regularidad o normatividad y, por ende, no puede ser considerada racista, dado que lo que quiere decir es algo así como "trabajaste muy bien, amor". El capataz, en cambio, rompe con cierta regularidad o normatividad y, por ende, puede ser considerado racista, dado que lo que quiere decir es algo así como "trabajaste muy bien, animal". En este caso, es la intención del hablante, al proferir (4), la que rompe con la regularidad o normatividad establecida.

Si lo anterior es correcto, como efectivamente parece ser el caso, entonces es fácil aceptar las siguientes dos ideas:

(A) Las acciones e intenciones de los hablantes se rigen por esquemas sociales regulados por normas.

(B) Las normas que regulan esquemas sociales son establecidas por el sistema de creencias de una comunidad. 
Es decir, a partir del sistema de creencias de una comunidad se establecen las normas y esquemas sociales que regulan las acciones de los hablantes. Por ejemplo, colgar a una persona está, bajo ciertos esquemas sociales, o bien respaldado por una ley, a lo cual se le llama ajusticiar, o bien en contra de una ley, a lo cual se le llama asesinar. O, bajo ciertos esquemas sociales, golpear a un niño está o bien respaldado por una aceptación social, a lo cual se le llama educar o corregir, o bien en contra de una ley, a lo cual se le llama violencia infantil. Tanto la ley como la aceptación social -o las prácticas atípicas consentidas, en el caso de prácticas sadomasoquistasson resultados o productos de un sistema de creencias de una comunidad que las establece, las asume y las ejecuta.

Si (A) y (B) son el caso, entonces:

(S) Los sistemas de creencias, y por ende los esquemas sociales regulados por normas, determinan qué acciones e intenciones pueden ser calificadas como violentas o racistas cuando se realizan aseveraciones.

Por ejemplo, en la época de la esclavitud, bajo su esquema social y su sistema de creencias, aseverar (4) no era calificado como racista, dado que no rompía con ningún principio establecido.

$\mathrm{Si}(\mathrm{S})$ es cierta, como defiendo, entonces:

(C) Una acción $\mathbf{x}$ pude ser violenta dentro de cierto sistema de creencias, aun cuando en otro sistema de creencias esa misma acción $\mathbf{x}$ no lo sea.

Una de las consecuencias de aceptar (C) es la siguiente: ${ }^{11}$

(F) Puede haber confrontaciones entre comunidades cuando una de ellas considera a una acción $\mathbf{x}$ violenta, mientras que otra no considera como violenta a esa misma acción $\mathbf{x}$.

Por ejemplo, una comunidad que hoy en día continuara regida por un esquema y sistema de creencias esclavista entraría en conflicto con el esquema social de otras comunidades, como las de occidente, que han abolido la esclavitud como resultado del cambio de su sistema de creencias.

Para mantener la armonía entre las comunidades, es decir, para bloquear (F), defiendo el siguiente principio:

(T) Hay que mantener una actitud de respeto hacia el sistema de creencias de comunidades diversas.

Por ejemplo, el Reino Unido continúa aceptando en su territorio que las mujeres de las comunidades árabes, a las cuales va dado asilo y refugio, lleven niqab o burka, aun cuando las mujeres británicas no acostumbren ello. Eso muestra que dentro de la 
política del Reino Unido está el respeto hacía el sistema de creencias de comunidades diferentes. Es verdad que otros países, como Bélgica y Holanda, han prohibido el uso del niqab y el burka en su territorio. Pero dichos países no han evaluado prohibir dichas prendas en países árabes por respecto, entre otras cuestiones políticas, hacia dichas comunidades. ${ }^{12}$

Si una comunidad quisiera tomar medidas en relación a lo que considera violento respecto a las acciones de una comunidad distinta tendría que:

(M) Apelar a un grupo independiente e imparcial que pudiera establecer condiciones de comunicación para abolir potenciales acciones de violencia.

Si Bélgica, digamos, considerara que llevar niqab o burka atenta contra la integridad de las mujeres, una de las razones del por qué se cree que prohibió llevarla en su territorio, y por dicha razón intentara prohibirla en el mundo entero, tendría que apelar a una entidad independiente imparcial, como la Organización de las Naciones Unidas, para erradicarla y no violar $(\mathrm{T})$.

Si (C) es verdadera, se sigue entonces que:

(D) Las acciones por sí mismas no son violentas, sino que bajo cierto esquema de creencias una acción $\mathbf{x}$ puede ser o no ser considerada violenta.

Por ello, para mantener un axioma que toda comunidad desea, a saber:

(P) Hay que mantener la estabilidad e integridad de los miembros de la comunidad, así como de su entorno social y natural,

defiendo que:

(E) Hay que examinar y evaluar constantemente los sistemas de creencias de las comunidades, ya que es allí donde están basados los esquemas sociales que norman y regulan las acciones de los individuos de la comunidad.

Es decir, es importante examinar y evaluar los sistemas de creencia de las comunidades y encontrar, a partir de un análisis conceptual, todas aquellas ideas que respalden creencias que impulsen el rompimiento de (P). Hacer ello permitirá corregir o actualizar la manera en la que se relacionan los individuos en la comunidad y en su entorno social y natural.

Por ejemplo, algunas comunidades han abolido la pena de muerte al haber adoptado la creencia de que dicha acción, aunque legal por mucho tiempo, atentaba contra la integridad o los derechos de los individuos, rompiendo con un principio que la comunidad también había establecido. 


\section{Criterio alterno para discernir acciones violentas}

En los casos (1), (2) y (3) se ha formulado una interpretación alterna a la que yo defiendo, la cual puede formularse de la siguiente manera:

(V) Una acción física o verbal $\mathbf{x}$ es violenta, aun si $\mathbf{x}$ es respaldada por alguna ley, consentimiento o aceptación social.

Esta tesis se fundamenta en el siguiente criterio:

(I) El uso de la fuerza y la intención de agredir por parte de una persona hacia otra basta para que una acción sea considerada violenta.

Si este criterio es correcto, y lo es también (V), entonces se sigue que en todos los casos mostrados en (1), (2), (3), e inclusive en (4), se ejerce violencia, solamente que en algunos de ellos esta violencia está justificada por leyes, consentimientos o aceptaciones sociales. Por lo tanto, de ser verdadera (V), todas las ideas que conforman mi propuesta, a saber, (R), (S), (C) y (D), serían falsas.

En palabras distintas, para que una acción sea violenta, se asegura con (V), es irrelevante que rompa o no cierta normatividad o regularidad establecida por una comunidad, la cual basa su esquema evaluativo en un sistema de creencias. Lo relevante es que halla una fuerza o intención de agredir por parte de una persona hacia otra. Por ello, no hay nada que respalde una acción para que no sea considerada violenta. La pregunta que surge, entonces, como resultado de esto, es la siguiente: ¿una ley, una práctica, una norma, o inclusive una intención, no puede justificar el uso de la violencia?

\section{Principio de permisibilidad}

Lo que defiendo es que no hay algo así como violencia justificada. Lo que hay - o a lo que se le llama erróneamente violencia justificada - es un caso de permisibilidad que hace que ciertas acciones sean eximidas de ser calificadas violentas. Las razones que ofrezco para defender esto son las siguientes.

Parto de esta idea:

(L) Las acciones son entidades que pueden clasificarse bajo principios.

Por ejemplo, está el conjunto de acciones que podríamos llamar $\mathbf{X}$, en el cual están las siguientes acciones primitivas: beber, comer, caminar, correr, observar, etc. Hay otro conjunto de acciones $\mathrm{Y}$ en el cual están las siguientes acciones placenteras: hacer el amor, ir al cine o al teatro, asistir a una charla o conferencia o seminario, 
etc. Hay otro conjunto de acciones $\mathbf{Z}$ en el cual están incluidas las siguientes acciones cognitivas: dormir, soñar, pensar, imaginar, etc.

Podríamos clasificar, así, el resto de acciones bajo ciertos principios. Dentro de esta clasificación estaría el conjunto de acciones violentas $\mathbf{V}$, en el cual estarían incluidas acciones físicas, verbales, imaginadas y pensadas que rompen o podrían romper con cierta regularidad o normatividad establecida por la comunidad.

Si una clasificación como la anterior puede establecerse, como efectivamente creo que es el caso, defiendo que:

(N) A ciertas acciones $\mathbf{X}$, aunque pertenecen a cierto conjunto $\mathbf{X}$, se les puede colocar en conjuntos diferentes, digamos en $\mathrm{Y}$ o Z $\mathbf{Z}$.

A esto es a lo que llamo el principio de permisibilidad, a saber: al principio que legitima poder mover una acción de su conjunto.

Por ejemplo, piénsese en la siguiente acción: besar, acción que pertenece, digamos, al conjunto $\mathbf{P}$, donde están incluidas acciones como acariciar, susurrar palabras de amor, cuidar, entre otras. Uno de los principios que establece a este conjunto es el de transmitir amor, deseo o placer. Sin embargo, la acción besar puede moverse al conjunto, digamos, $\mathbf{N}$, el cual está integrado por acciones de traición. El caso más representativo en la historia que respalda esta idea es el beso que le dio Judas a Jesús: el beso pasó de ser un acto de amor a un acto de traición. Por lo tanto, dicha acción pasó del conjunto $\mathbf{P}$ al conjunto $\mathbf{N}$.

Lo mismo sucede, sostengo, con el conjunto de acciones violentas: hay acciones que pueden moverse a diferentes conjuntos. Golpear a alguien podría moverse del conjunto de acciones que lastiman, al conjunto de acciones que generan placer o al conjunto de acciones que corrigen conductas. Asimismo, colgar a alguien podría moverse al conjunto de acciones que ajustician. Todo ello está justificado por el principio de permisibilidad.

El principio de permisibilidad, mantengo, es establecido por la comunidad. Es la comunidad la que lo regula y le ponelímites. Es decir:

(T) La comunidad permite o deniega o abole que se empleé el principio de permisibilidad en función de su sistema de creencias.

Por ello, y aquí apelo una vez más a (E), hay que examinar y evaluar regularmente los sistemas de creencias de las comunidades, ya que es en ellos donde están basados los esquemas sociales que norman, regulan o dan permisibilidad a las acciones de los individuos, y de donde se podría erradicar todo tipo de acción que pueda romper reglas o normas. 


\section{Objeciones al axioma (P) y al principio de permisibilidad (N)}

Alguien podría argumentar, a modo de objeción, que el sistema de creencias de una comunidad puede ser en sí mismo violento. El desequilibrio del poder de una sociedad podría establecer creencias y normas que instauren prácticas violentas como regla, adquiriendo estas una apariencia de no serlo, al ser aceptadas socialmente.

Un ejemplo de ello es el sistema de creencias de las culturas islámicas, las cuales respaldan acciones que inhiben la libertad de las mujeres de mostrar públicamente no solamente sus rostros, sino también sus cuerpos, estando sometidas a los designios masculinos de la comunidad en general.

Si lo anterior es así, (P) sería falsa, dado que no toda comunidad desea mantener la estabilidad e integridad de sus miembros, así como de su entorno social y natural, sino que le interesa desestabilizarla para tener poder y control sobre ella de manera violenta.

Mas aún, en una sociedad en la que un cierto grupo prevalece en la gran mayoría de las esferas del poder, y establece las costumbre y las reglas generales, consentir con esas reglas implica, para un grupo que no tiene control sobre ellas, sobrevivir y evitar violencias de grado elevado, como acontece con las mujeres en las culturas islámicas.

En estos casos, el principio de permisibilidad (N) es de tipo violento, al coercionar a un grupo minoritario de individuos. Por ello, es difícil pensar en un principio de permisibilidad que regule de manera objetiva y neutral las acciones de los individuos.

\section{Defensa del axioma (P) y del principio de permisibilidad (N)}

Hay que hacer una distinción entre violencia y otros sustantivos que se acercan a dicho concepto, como agresión, maltrato, brutalidad, ferocidad, bestialidad, crueldad, atrocidad, barbarie, entre otros. Aunque muchos de estos conceptos pueden ser asociados con el concepto violencia, no siempre es así, siendo diferentes de este.

Pensemos, por ejemplo, en la siguiente oración:

(5) Un león atacó a una hiena hasta devorarla completamente.

A dicho acto podríamos calificarlo de feroz, atroz, brutal o bestial, pero difícilmente de violento. La razón de ello es que el concepto de violencia se usa exclusivamente al interior de un sistema social constituido por creencias, las cuales establecen reglas o normas que regulan las acciones de los individuos. Romper con dichas reglas o normas sería un acto de violencia, dado que rompen con cierta regularidad o 
normatividad social. El león, al atacar a la hiena hasta devorarla completamente, no rompe con ninguna regularidad o normatividad social, sino que su acto está fuera de un sistema social, por ello es que su acción es calificada como atroz o brutal, pero no como violenta.

Pensemos ahora en un caso diferente, como el canibalismo o el sacrificio humano. Digamos que escuchamos a alguien proferir la siguiente oración:

(6) Los mexicas comían y sacrificaban hombres a sus dioses.

¿Podemos calificar a los mexicas de violentos? A diferencia del león, ellos contaban con un sistema de creencias, el cual regía un esquema social que regulaba y normaba las acciones de los individuos. Sin embargo, justamente por ello es que difícilmente podríamos calificarlos de violentos, dado que el canibalismo y el sacrificio estaba regulado por normas y reglas de dicha comunidad. Pese a ello, nada nos impide de denominarlos crueles, atroces o bárbaros, dado que la manera en la que lo hacían era verdaderamente sanguinaria.

Lo mismo sucede con el sistema de creencias islámico: no podemos calificarlo de violento, dado que no rompe regla o norma al interior de su sistema, al obligar a las mujeres a cubrir su rostro o cuerpo. Sin embargo, sí podemos llamarlo autoritario, agresivo, opresor, brutal, cruel o atroz. Si deseamos que dicho sistema deje de serlo, habría que trabajar en generar e instaurar reglas y normas para eliminar dichas acciones, colocándolas, por medio de $(\mathrm{N})$, en el grupo de acciones violentas.

Para hacer lo anterior, como defiendo con (E), hay que examinar y evaluar constantemente los sistemas de creencias de las comunidades, ya que es allí donde están basados los esquemas sociales que norman y regulan las acciones de los individuos de la comunidad, y donde podemos instaurar nuevas formas de regular o normar las acciones, moviéndolas, por medio de $(\mathrm{N})$, del conjunto de acciones que son agresivas, opresoras, brutales, crueles o atroces, al conjunto de acciones violentas.

Es verdad que al instaurar dichas normas o reglas se puede optar por acciones violentas, las cuales rompan cierta normatividad o regularidad establecida por la comunidad. Pero también se puede optar por mecanismos distintos, los cuales no impulsen ello. Un muy buen ejemplo de esto son las acciones que ha tomado el Ejercito Zapatista de Liberación Nacional (EZLN) en México, el cual ha optado por el dialogo y la resistencia, ${ }^{13}$ para que el gobierno mexicano reconozca los derechos de las comunidades indígenas, tales como hablar su propia lengua y preservar sus costumbres frente a las prácticas occidentales.

Por lo tanto, no es que (P) sea falso o que (N) sea violento. Hay grupos de poder que pueden desestabilizar sociedades para fines personales. Sin embargo, las comunidades no se reducen a ellos, por más poder que tengan. Se pueden tomar medidas diversas para resistir a ellos, tratando de alcanzar una estabilidad e integridad social 
descrita por (P), usando el principio de permisibilidad (N), para colocar acciones atroces, crueles, bestiales y de maltrato en el conjunto de acciones violentas.

En suma, cuando hablamos de violencia, lo hacemos al interior de un sistema de creencias que establece normas y reglas, las cuales rigen las acciones de los individuos de una comunidad. Si la acción de un individuo rompe cierta regularidad establecida por dichas reglas o normas, entonces decimos que su acción es violenta. Solamente en este caso exclusivo podemos hablar de violencia. El resto de casos han de ser calificados como agresivos, crueles, brutales, atroces, entre otros muchos, si no rompen regla o norma alguna.

\section{Ventajas teóricas de mi propuesta}

¿Cuál es la ventaja teórica, sin embargo, de decir que ciertos actos no son violentos dentro de ciertas culturas, como el sacrificio humano, el canibalismo o la esclavitud, por ajustarse simplemente a ciertas normas sociales? ¿Acaso no hay violencias estructurales que están de acuerdo con normas culturales de una sociedad? Más aun, ¿debe haber respeto a los actos que deberían ser considerados violentos solamente porque no lo son en ciertas culturas?

Las ventajas teóricas que trae mi propuesta son las siguientes. Primeramente, nos permite discernir conceptualmente el término violencia de otros conceptos cercanos, como los son crueldad, maltrato, agresividad, brutalidad, ferocidad, barbarie, opresión, etc. Ello nos da la oportunidad de comprender que, digamos, crueldad o atrocidad no siempre se asocian con violencia. Por ejemplo, alguien podría ver una crueldad atroz en la corrida de toros, pero ello no lo legitimaría a decir que es violenta, dado que dicha práctica, al estar legalizada, no rompe regla o norma alguna.

Una vez entendidad la diferencia conceptual, podemos evaluar qué casos caen dentro del término violencia. Mas aún, podemos evaluar qué casos deberían estar dentro dicho término. Por ejemplo, motivada por la crueldad y atrocidad que ve en la corrida de toros, una persona podría, apelando a razones, tratar de establecer reglas y normas que la prohíban. Estas razones no pueden ser la crueldad o atrocidad que hay en dicha práctica, dado que muchas prácticas sociales, que son legítimas para el ser humano, podrían ser calificadas como tales, como la matanza de cerdos, vacas y pollos para el consumo humano, la experimentación con ratones para nuevas investigaciones, como el SARS-Cov-2, o la simple fumigación de conejos que son considerados plagas en ciertas comunidades.

Las razones no pueden basarse, así, en la crueldad y atrocidad, las cuales serían motivos que podrían llevar a alguien a establecer reglas o normas que regulen la corrida de toros, pero faltando aun así razones. Una de estas razones podría ser que la diversión, el entretenimiento o el deporte no puede estar basado en el sufrimiento 
de seres vivos, sean ya seres humanos o animales. Esta razón, acompañada de otras, podría generar propuestas de regular o prohibir la corrida de toros. De aceptarse, quien quiera que ejecute dicha práctica estaría rompiendo cierta regularidad social, lo cual podría ser ya calificado como violento.

Esto es lo que nos permite mi propuesta, generar el aparato conceptual, a partir de diferenciar la aplicación de los conceptos de violencia con otros que pueden asociársele, para ofrecer propuestas teóricas y pragmáticas en busca de la estabilidad social y el buen relacionamiento entre los individuos de la comunidad.

La ventaja teórica, así, de decir que ciertos actos no son violentos dentro de ciertas culturas, como el sacrificio humano, el canibalismo o la esclavitud, por ajustarse simplemente a ciertas normas sociales, yace en entender que ello no impide calificarlas como sanguinarias, bárbaras, opresoras, feroces o atroces. Asimismo, nos permite comprender que no es por calificarlas de esta forma que se luchó por erradicarlas, al menos no necesariamente, sino que fue por razones de igualdad social entre los miembros de las comunidades, no importando su condición social, étnica o racial. Esto es lo que nos permite entender mi propuesta.

Ahora bien, a lo que se le llama violencia estructural no es sino a una actitud de dominación que tienen ciertos miembros de poder en las comunidades, los cuales gobiernan o son de influencia económica, política y social. Estas actitudes de dominación promueven, o pueden promover, acciones de maltrato, crueldad u opresión, al establecer ciertas reglas o normas que van en contra de la comunidad, pero a favor de los intereses de estos pequeños grupos. No obstante, estas reglas y normas no podrían ser consideradas violentas, en tanto que no atenten contra la regularidad que ha sido establecida, aunque pueden generar acciones de crueldad, opresión o maltrato.

Si lo anterior es así, como creo que es el caso, podemos sustituir la expresión violencia estructural por actitud de dominación estructural. Las actitudes de dominación estructural promueven, o pueden promover, reglas y normas para someter al resto de los individuos de una comunidad a favor de ciertos beneficios de un grupo minoritario de poder. Los grupos no influyentes, sin embargo, pueden tomar acciones para contrarrestar dichas actitudes de dominio, estableciendo reglas y normas que las legitimen como violentas. Ello, como dije anteriormente, puede llevar a alterar la regularidad social, al haber revueltas, revoluciones o guerras. Pero muchas veces se requiere ello para cambiar estructuras sociales que atentan contra (P). Claramente, también se puede optar por la vía de la legalidad, al tratar de cambiar o incluir reglas y normas que beneficien a la comunidad.

Asimismo, el respeto hacia las acciones atroces, sanguinarias $u$ opresoras que vemos en otra sociedad, las cuales se suelen confundir con violencia, pero que no lo son por estar reguladas al interior del sistema de la comunidad, no yace en tener una actitud pasiva o contemplativa, sino en cambiarlas, si así se desea, por medio de 
la legalidad apelando a instancias independientes, quizá internacionales, las cuales garanticen una comunicación entre comunidades.

Para ello, por ejemplo, se podría recurrir a ciertas organizaciones mundiales para tratar de eliminar el uso del burka por parte de las mujeres en las culturas árabes, o, también, disminuir de Brasil la población negra en los trabajos más precarios por la falta de oportunidades sociales que tiene ese grupo étnico, ${ }^{14} \mathrm{o}$, asimismo, la extinción de la pobreza indígena, al regularizar sus práctica culturales, las cuales muchas de ellas tienen como resultados productos que son plagiados o explotados. ${ }^{15}$

El respeto, así, no consiste en aceptar las acciones sanguinarias, atroces u opresoras de otras comunidades, las cuales podríamos calificar de violentas dentro de nuestro sistema de creencias, por alterar nuestra normatividad o regularidad social. Consiste, primeramente, en discernir dichas acciones sanguinarias, atroces u opresoras de acciones violentas, para después, por medio de la legalidad, tratar de instaurar dichas acciones, apelando quizá a entidades independientes que garanticen el diálogo, dentro de reglas que las prohíban. Esto es lo que nos proporciona mi propuesta.

\section{8. Últimas consideraciones: intención y fuerza}

Se podría argumentar, antes de concluir, que el simple rompimiento de reglas o normas no basta para considerar una acción $\mathbf{x}$ violenta. Se requiere un criterio mucho más robusto, el cual integre al menos dos requisitos extras, a saber:

(i) La intención de un individuo de romper normas o reglas.

(ii) Una fuerza física o verbal que acompañe a la intención.

Si no está acompañado dicho criterio de una intención junto con una fuerza física o verbal, ¿llamaríamos violentas a acciones que rompen normas o reglas de manera accidental? ¿Llamaríamos violentos a fenómenos físicos que destruyen ciudades? ¿Llamaríamos violentos a virus o bacterias que atentan contra la vida de poblaciones enteras? ¿Llamaríamos violentos a animales que atentan contra la vida de personas $\mathrm{u}$ otros seres vivos?

Considero que $(R)$ no requiere robustecerse. Lo que establece $(R)$ es una condición mínima para discernir como violenta una acción. Pero (R) por sí misma no basta. Se requiere también de $(\mathrm{N})$, principio que legitima que una acción pueda ser movida de un conjunto a otro.

Por ejemplo, pensemos en la siguiente oración:

(7) La taza fue quebrada mientras cenábamos.

$\mathrm{Si}$ (7) es aseverada en un contexto donde la taza es quebrada mientras se intenta alcanzar el postre, calificaremos a dicha acción como accidental. Sin embargo, si (7) 
es aseverada en un contexto donde la taza es quebrada como muestra de desprecio hacia los anfitriones de la casa, calificaremos a dicha acción como violenta.

Lo que hace que en el primer contexto la acción no sea considerada violenta no es que no exista la intención de querer quebrar la taza, intención que aparece en el segundo contexto, sino que es el principio de permisibilidad que coloca a dicha acción en el conjunto de acciones accidentales.

Esto es, para determinar una acción como violenta, apelar a la intención del individuo es irrelevante, dado que no habría manera de saber si el individuo ejecutó su intención. Hay casos donde tazas son aparentemente quebradas de manera accidental, confesando confidencialmente después el que lo hizo que fue completamente intencional. Más aun, hay casos donde tazas son quebradas empleando la fuerza de manera accidental: piénsese en una situación donde un hombre arroja una taza fuertemente al resbalársele ésta de la mano.

No es un parámetro, entonces, la intención y la fuerza, dado que no hay manera de identificar si en una acción el individuo las empleó. Lo que sí es un paramento es (R) y (N). Con ellos, dado el contexto, acciones que retratan oraciones como (7) pueden ser consideradas o como accidentales, aplicando el principio de permisibilidad, o como muestras de desprecio, y por ello violentas.

Lo mismo sucede con fenómenos físicos, virus o bacterias que destruyen ciudades y poblaciones. Aunque parece que dichos sucesos rompen reglas, como las de atentar contra los bienes materiales o la vida de las personas, no lo hacen. Y esto no se debe a que no se les pueda atribuir intención alguna, sino a que, por el principio de permisibilidad $(\mathrm{N})$, dichas acciones se les coloca en el conjunto de catástrofes naturales.

Algo similar acontece con animales que matan o intentan atacar personas $\mathrm{u}$ otros seres vivos. No es que con sus acciones rompan reglas, sino que, a dichas acciones, por $(\mathrm{N})$, se les coloca en el conjunto de acciones de seres que no pertenecen a nuestras sociedades o como seres naturales.

Obsérvese que los animales que matan o atacan a alguien tienen la intención de hacerlo, y dicha acción la acompañan de una fuerza física. Pero no por ello se puede decir que ejercen acciones violentas. Decimos, por el contrario, que son animales agresivos o bravos. De ser considerados violentos, dichos animales tendrían que ser sometidos a juicios legales, con defensas de por medio. Pero no se hace eso en las sociedades. Lo que se hace es aniquilar a dichos animales, pero ello no por haber ejercido una acción violenta, sino por ser un peligro para la sociedad, al ser considerados animales feroces.

Es verdad que en la cotidianidad se van calificando como violentos a ciertos animales, virus, fenómenos y accidentes. Lo que legitima a ello no es el rompimiento de reglas, sino ciertas licencias lingüísticas que nos permiten hablar de manera figurada o metafórica. Estas licencias nos autorizan a decir que, por ejemplo, el coronavirus-19 
es un virus muy violento, o que lo es también el león o los terremotos, o un choque de autos en la carretera. Pero hacer ello no es sino establecer una semejanza con las acciones que, dentro de los sistemas sociales y de creencias, pueden considerarse violentas. Así, los accidentes, fenómenos, virus o animales solamente rompen reglas de manera figurada.

En suma, toda acción que es considerada violenta toma base o se legitima al interior de un sistema de creencias, sistema que, a través de normas o reglas, regula las acciones de los individuos. Las acciones por sí misma no pueden ser calificadas como violentas, sino que son los sistemas de creencias los que determinan si una acción rompe o no con una regla.

\section{Referencias}

Arendt, H. 1970. On Violence. New York: A Harvest Book Harcourt, Inc.

Arvizu Arrioja, J. 2019. Aprueban ley contra plagio de cultura indígena en comisiones del Senado. El Universal, noviembre 30. https://www.eluniversal.com.mx/nacion/politica/apru eban-ley-contra-plagio-de-cultura-indigena-en-comisiones-del-senado

Coady, C. A. J. 2008. Morality and Political Violence. Cambridge University Press.

Foucault, M. 1977. Discipline and Punish. The Birth of the Prison. New York: Vintage Books.

Góes, P. 2011. Brasil: Censo "Revela" que Maioria da População Brasileira é Negra. GlobalVoices, novembro 24. https://pt.globalvoices.org/2011/11/24/brasil-censo-populacao-negra/.

Heitmeyer, W. \& Hagan, J. 2003. International Handbook of Violence Research. New York: Kluwer Academic Publishers.

Imbuch, P. 2003. The Concept of Violence. In: Heitmeyer and Hagan 2003, pp.13-39.

Mena, F. \& Borges, D. 2020. Racismo gera diferença salarial de $31 \%$ entre negros e brancos, diz pesquisa. Folha de S. Paulo, janeiro 6., https://www1.folha.uol.com.br/mercado/2020/ 01/racismo-gera-diferenca-salarial-de-31-entre-negros-e-brancos-diz-pesquisa.shtml

Pontara, G. 1978. The concept of violence", Journal of Peace Research 15(1):19-32.

Ray, L. 2011. Violence and Society. United Kingdom: Sage Publications.

Rodriguez Martines, M. 2019. ¿Qué paises europeos prohíben el burka? Euronews, febrero 27. https://es.euronews.com/2018/08/08/-que-paises-europeos-prohiben-el-burka-

Shaffer, J. (ed.). 1971. Violence Award Winning Essays in the Council for Philosophical Studies Competition. New York: David McKay Company.

Vorobej, M. 2016. The Concept of Violence. New York: Routledge.

Velleman, D. J. (2013). Foundations for Moral Relativism. OpenBook Publishers.

Zizek, S. 2008. Violence. New York: Picador.

\section{Notas}

${ }^{1}$ No es mi intención evaluar y discutir la diversidad de propuestas que hay respecto al tema de violencia. Solamente me limitaré a contextualizarlas y a señalar lo que algunos estudiosos han intentado hacer, dado que el objetivo del presente artículo es plantear una 
propuesta sobre la violencia y contrastarla con una postura básica sobre ella, elaborando y respondiendo a algunas objeciones. Para el caso de propuestas que explican la violencia, puede, confrontarse la magistral compilación que hace Shaffer (1971). Aunque todos los artículos son valiosos, sugiero consultar particularmente el artículo de Robert L. Holmes: "Violence and Nonviolence", donde explora el tema de la guerra de manera detallada.

${ }^{2}$ Cfr. Foucault 1975, pp.170-94.

${ }^{3}$ Cfr. Zizek 2008, pp.206-7.

${ }^{4}$ Cfr. Ray 2011. Particularmente, los capítulos 4. Spaces of Violence y 7. Explaining Homicide.

${ }^{5}$ Cfr. Coady (2008). En especial, mírese el capítulo 7. The Problem of Collateral Chalenge.

${ }^{6} \mathrm{Cfr}$. Arendt 1970, pp.3-7.

${ }^{7}$ Cfr. Vorobej 2016, pp.2-4.

${ }^{8}$ Cfr. Imbuch 2003, pp.13-15.

${ }^{9}$ Cfr. Pontara 1978, pp.19-20.

${ }^{10} \mathrm{Cfr}$. Heitmeyer y Hagan 2003. En particular, todos los artículos de la sección II. Research on Violence: An Interdisciplinary Approach with a Focus on Social Science.

${ }^{11}$ Un relativismo es una consecuencia teórica de mi propuesta. Considero que se le puede hacer frente, no descartándolo, sino asumiéndolo, dado que es un relativismo estrecho, y no amplio (Cfr. Velleman (2013)). Es decir, la razón yace en que, con mi propuesta, no me comprometo a defender que toda propuesta axiológica es legítima, al menos no dentro de un sistema de creencias y de normas de una misma comunidad. Es verdad que defiendo que diferentes comunidades pueden tener diferentes sistemas de creencias y diferentes normas. Pero dentro de cada una de estas comunidades no hay cabida sino para un esquema social único, el cual puede ser modificado en el transcurso del tiempo y ajustarse a necesidades sociales pertinentes. Es con este tipo de relativismo que simpatizo. Esta idea, no obstante, la desarrollaré y defenderé en otro artículo, no solamente por la extensión que conlleva hacerlo, sino porque mi objetivo aquí es explicar mi propuesta, mostrando las ideas que la fundamentan.

${ }^{12}$ Cfr. Rodriguez Martines 2019.

${ }^{13}$ Cfr. CCIR-CG, "Tercera declaración de la selva Lacandona", enero, 1995, en https:// enlacezapatista.ezln.org.mx/.

${ }^{14}$ Cfr. Mena \& Borges 2020; Góes 2011.

${ }^{15}$ Cfr. Arvizu Arrioja 2019.

\section{Agradecimentos}

El presente artículo es producto de una serie de conferencias impartidas en sedes alternas de la Universidad Autónoma de Tlaxcala - en su Departamento de Filosofía y Centro de Investigaciones Interdisciplinarias Sobre Desarrollo Regional (CIISDER) —, de la Universidad Vasco de Quiroga, Morelia, Michoacán, y de la Universidad Benemérita de Puebla — su sede en Teziutlán - . Quiero agradecer al público que escuchó las conferencias, y a dos árbitros de la revista Principa, sus comentarios, los cuales me sirvieron para mejor las ideas que desarrollo en este ensayo. Quiero agradecer también a mi amigo Víctor Cantero Flores por discutir amplia y detalladamente las ideas que aquí presento. Mi agradecimiento especial es para Magdalena Sam, por darme la oportunidad de presentar este artículo, o parte de este, en 
el CIISDER; asimismo, por su apoyo incondicional que me brindó cuando llegué a México, después de haber estado yo largos años en Inglaterra. 